\title{
A PESQUISA EM HISTÓRIA DA EDUCAÇÃO A PARTIR DE VISITAÇOEES A MUSEUS: INTERAÇÕES EM TORNO DA MEMÓRIA E DO PATRIMÔNIO CULTURAL
}

\author{
RESEARCHING HISTORY EDUCATION TAKING INTO \\ ACCOUNT VISITS TO MUSEUMS: INTERACTIONS \\ BETWEEN MEMORY AND CULTURAL PATRIMONY
}

Maria Julieta Weber Cordova*

Resumo: A atividade extensionista "Patrimônio Cultural e Memória: fontes para a pesquisa em História da Educação" foi realizada em forma de curso, durante o segundo semestre de 2016, e teve como objetivo aprofundar o conhecimento no campo específico da história da educação, estabelecendo relações com os estudos sobre memória e patrimônio cultural no Brasil. A partir das visitações ao Museu Paranaense (Curitiba - PR) e ao Museu Nacional de Imigração e Colonização (Joinville - SC), promoveu-se a interação entre estudantes de graduação, de pós-graduação e profissionais responsáveis pelas visitações aos museus analisados. Compreendeu-se que proporcionar viagens de estudos no âmbito da formação acadêmica, no caso em específico para a área da Educação, possibilita um redimensionamento curricular e incentiva a formação de professores/as pesquisadores/as. Foram evidenciadas diferenciadas possibilidades de compreensão de diversas fontes para pesquisas correlacionadas à Memória, História e História da Educação.

Palavras chave: História da educação; memória; patrimônio cultural.

\begin{abstract}
The outreach activity Cultural Patrimony and Memory: sources for research in History Education was carried out through a course during the second semester of 2016. It aimed at improving the knowledge in history education, establishing a correlation to the studies on memory and cultural patrimony in Brazil. The visits to the Paranaense Museum (Curitiba-PR) and to the National Museum of Immigration and Colonization (Joinville-SC) promoted interaction among undergraduate and graduate students and professionals responsible for the visits in the museums. It was understood that providing visits to historic places within the scope of academic training, in this specific case the area of education, it is possible to adjust the curricular program and to motivate students for the educational reasearch field. It demonstrates different possibilities to understand the sources for research that are correlated to memory, history and history of education.
\end{abstract}

Keywords: History education; memory; cultural patrimony. 


\section{Introdução}

A atividade extensionista "Patrimônio Cultural e Memória: fontes para a pesquisa em História da Educação" foi realizada em forma de curso, durante o segundo semestre de 2016, tendo como público alvo estudantes de graduação e pós-graduação da Universidade Estadual de Ponta Grossa. O projeto teve como objetivo trabalhar diferenciadas fontes para a pesquisa em história da educação, proporcionando experiências educativas em espaços museais, a partir das visitações ao Museu Paranaense (Curitiba - PR) e ao Museu Nacional de Imigração e Colonização (Joinville - SC).

Buscou-se, assim, aprofundar o conhecimento no campo específico da história da educação, estabelecendo relações com os estudos sobre memória e patrimônio cultural no Brasil. Ao se promover a interação entre estudantes de graduação e pósgraduação, compreendeu-se que proporcionar viagens de estudos no âmbito da formação acadêmica, no caso em específico para a área da Educação, possibilita um redimensionamento curricular e incentiva a formação de professores pesquisadores.

Totalizando 29 (vinte e nove) integrantes entre estudantes e docentes, foram indicadas leituras de aprofundamento da temática, visando o estudo e a discussão de pesquisas relacionadas com o objetivo da proposta. Ao final do curso, solicitou-se a escrita de relatório final, devendo este contemplar, de forma temática, aspectos que tratassem da relação entre memória, história e história da educação, decorrentes das leituras indicadas e das visitações ao Museu Paranaense (Curitiba - PR) e ao Museu Nacional de Imigração e Colonização (Joinville - SC).

Dentre as indicações de leitura, ressaltem-se os estudos de Maurice Halbwachs sobre memória coletiva; Pierre Nora, sobre memória, história e a problemática dos "lugares de memória"; Michael Pollak e a sua discussão sobre memória, esquecimento e silêncio; Myrian Sepúlveda dos Santos e o debate as políticas culturais nos museus brasileiros; e de Maria Stephanou, sobre as problematizações em torno do tema da memória e história da educação.

O referido relatório deveria, também, apresentar questões referentes às experiências decorrentes das visitações e das exposições museais observadas, adotando-se critérios de normalização de trabalhos científicos, com um mínimo de 40 (quarenta) linhas, e contemplando fontes documentais e bibliográficas utilizadas. Quanto aos instrumentos para avaliação, tiveram como critérios de pontuação a participação nas atividades propostas e o relatório escrito, a ser entregue após o período de uma semana do término da última viagem de estudos.

As visitações ao Museu Paranaense (Curitiba PR) e ao Museu Nacional de Imigração e Colonização (Joinville - SC) foram agendadas com antecedência, para que os cursistas pudessem usufruir das visitas com acompanhamento /monitoramento dos profissionais responsáveis pelos respectivos museus.

\section{Visitações aos museus: o debate em torno da memória, da história e da história da educação}

Pierre Bourdieu, em $\mathrm{O}$ amor pela arte: os museus de arte na Europa e seu público (2007), ao pesquisar sobre as condições sociais da prática cultural, discutindo, dentre outras questões, sobre a "verdade oculta do gosto culto", argumenta que os museus, ainda que abriguem tesouros artísticos, encontram-se, paradoxalmente e ao mesmo tempo, abertos a todos, mas interditados à maioria das pessoas (BOURDIEU, 2007, p. 165). Os museus que abrigam acervos históricos, tradicionalmente, constituem-se em espaços onde se guardam objetos representativos de uma história oficial e, portanto, distantes do cotidiano vivenciado por sujeitos que não estejam diretamente ligados aos feitos de uma memória nacional, regional e/ou local: "No Brasil, há uma forte tendência a se privilegiar nos estudos das questões nacionais as suas especificidades constituintes, sejam elas nacionais, regionais, sejam locais" (SANTOS, 2017, p. 54).

Entretanto, diferenciados pensamentos e algumas práticas educativas de interação e diálogo com o público visitante têm problematizado o lugar de representação do museu nas sociedades onde se inserem, seja no tocante às questões curriculares que envolvem a Educação Básica e o Ensino Superior, seja na formulação de políticas culturais. Myrian Sepúlveda dos Santos (2017, p. 53) atenta que:

\begin{abstract}
Ao analisar as transformações das últimas décadas, Huyssen ressalta que, talvez, pela primeira vez na história, o museu, em seu sentido mais amplo, tenha assumido o lugar do filho favorito entre as instituições culturais. O museu, como espaço da preservação da cultura das elites e do discurso oficial, teria sido substituído por uma instituição que se abre aos meios de comunicação de massa e ao grande público [...]. Mas o que sabemos nós sobre os museus brasileiros?
\end{abstract}

Para responder a esta pergunta é necessária a leitura de pesquisas já realizadas sobre a própria representatividade dos museus brasileiros e sua relação com a história e a memória, assim como levar em conta alguns elementos imprescindíveis ao campo específico da museologia. Porém, para além das leituras, conhecer museus implica, necessariamente, visitá-los e, para isso, compreende-se que é fundamental inteirar-se do debate entre História e Memória, especialmente na história recente, momento em que, segundo Pierre Nora, evidencia-se a 
"curiosidade pelos lugares onde a memória se cristaliza e se refugia", pois "se há locais de memória é porque não há mais meios de memória" (NORA, 1993, p. 7).

Nessa direção, pensar em memória é suscitar o debate do esquecimento e do silêncio, apontando para a necessária e vital necessidade da discussão sobre as minorias e as diferenciadas experiências de vida que não se encontram, muitas vezes, guardadas em forma de acervos museais, mas que, por isso mesmo, remontam a aspectos de violência simbólica, camufladas justamente pelo silêncio ou esquecimento. Se há silêncio, certamente há processos de cristalização da memória que reverberam em formas de percepção da memória coletiva e de "gestão de memória".

Entretanto, ao se problematizar a memória oficial, estará também se problematizando possibilidades de interpretação da memória coletiva uma dessas possibilidades está na história oral: inscrevem e a delimitação das questões também encontra-se circunscrita a um campo de possibilidades. Assim, mais do que professar qual o posicionamento "mais acertado" creio que seja fundamental podermos nos colocar diante do leque de problematizações postas até o momento, detendo-nos na sua compreensão e implicações para nosso metiér de pesquisadores. (STEPHANOU, 2017, p. 133).

As implicações de como são tratadas as questões que envolvem a memória no estudo histórico serão, portanto, centrais para as percepções do próprio campo da história da educação. Promover alternativas pedagógicas que viabilizem questionamentos como estes são fundamentais. Nesse sentido, percebeu-se que visitações aos museus são alternativas necessárias para diferenciadas maneiras de compreender esses espaços enquanto fontes extremamente ricas para pesquisas em história da educação.

\section{Uma experiência extensionista em espaços museais}

O trabalho pedagógico realizado pela ação dos sujeitos, que pensam e vivenciam o cotidiano dos museus, corresponde às demandas sociais que sustentam a relação desses espaços com a sociedade onde se inserem. É a partir do trabalho de monitoramento das visitas que se pode experienciar a interação do público visitante em correspondência com os objetivos de gestão intencionados pelos profissionais ligados ao campo da museologia.

A primeira viagem foi ao Museu Paranaense (Curitiba - PR). Por meio das atividades de monitoramento, os cursistas tiveram contato com a história do patrimônio edificado que abriga o Museu desde 2002, monumento este tombado em 1987. Embora inaugurado em 1876, somente em 1882 tornou-se oficialmente pertencente ao governo paranaense.

Após ocupar seis sedes na região central de Curitiba, atualmente encontra-se instalado no "Palácio São Francisco", prédio construído com finalidade residencial por um comerciante de carnes da cidade, cuja fachada principal pode ser parcialmente visualizada na Fotografia 1, registrada pelos cursistas. Posteriormente, o prédio foi sede do governo regional, desde 1938, no período do governo de Manoel Ribas, até o mandato de Bento Munhoz da Rocha Netto (1951-1954); foi um espaço também utilizado pelo Tribunal Regional Eleitoral e pelo Museu de Arte do Paraná (MUSEU Paranaense, 2017). 


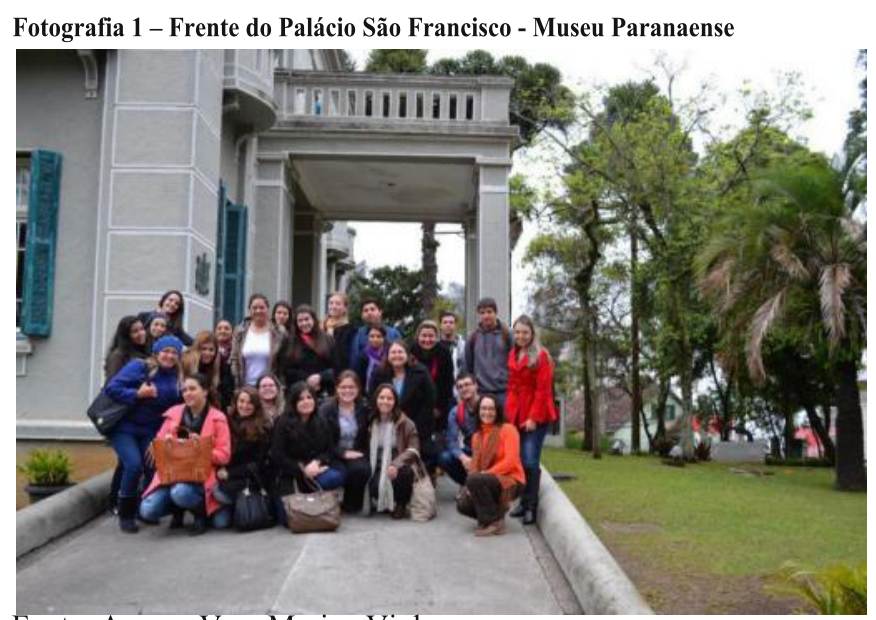

Fonte: Acervo Vera Marina Viglus

O Museu Paranaense conta com um setor educativo responsável por viabilizar, ao público em geral, orientações nas visitações, mas se voltando, especialmente, para o atendimento às instituições de educação básica e superior. Assim, durante a visita, demonstrada na Fotografia 2, os cursistas puderam usufruir de informações diversas sobre as exposições permanentes, que se constituem a partir das áreas de antropologia, arqueologia e história, com ênfase para o "Pavilhão da História do Paraná", que conta como metodologia de exposição uma "linha do tempo" desde 8000 anos antes da Era Comum até o século XX.

Fotografia 2 - Sala de exposições - Museu Paranaense

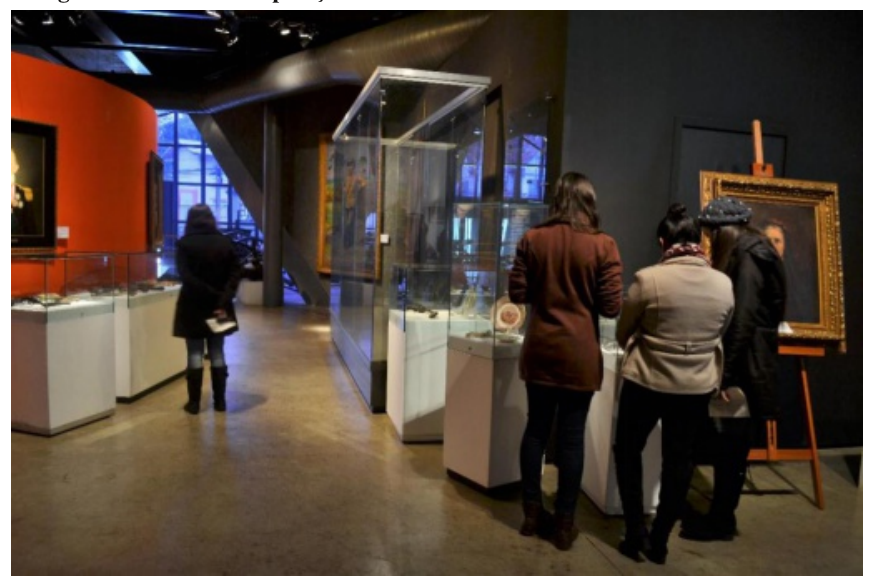

Fonte: Acervo Vera Marina Viglus

Em alguns momentos, as exposições evidenciaram a interlocução com a história da educação, por meio de objetos e fotografias que remeteram ao cotidiano de escolas locais e de alguns fragmentos biográficos de professores e professoras, com especial destaque para fins do século XIX e primeira metade do século XX, conforme se pode evidenciar na Fotografia 3, na representação expositiva de uma imagem sobre a confecção de bandeiras na Escola Profissional Feminina, no período da primeira metade do século XX, em Curitiba. Dentre as exposições temporárias, ressalta-se uma exposição sobre a história da primeira Escola de Artes do Paraná, intitulada "Memória: 130 anos do Centro Estadual de Capacitação em Artes Guido Viaro".

Fotografia 3 - Confecção de bandeiras por uma escola feminina - Museu Paranaense

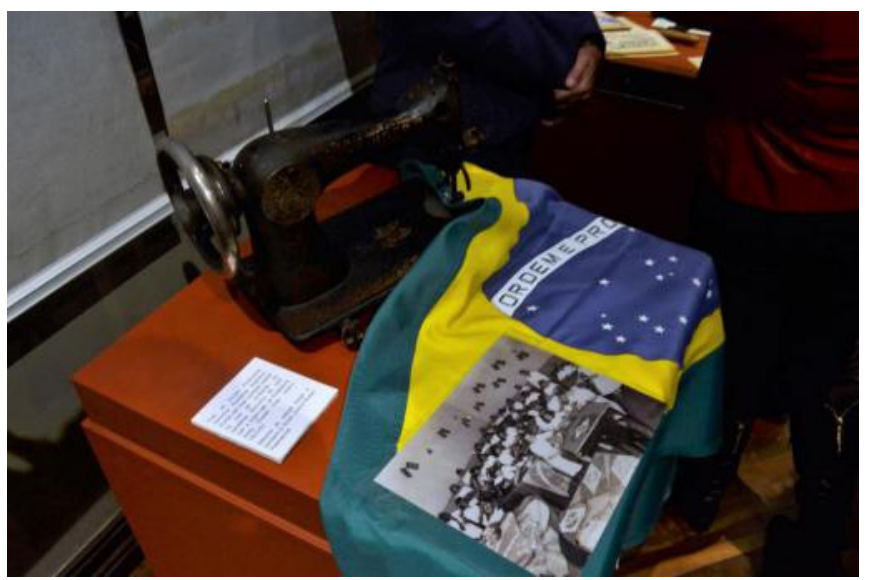

Fonte: Acervo Vera Marina Viglus

O segundo museu visitado foi o Museu Nacional de Imigração e Colonização (Joinville - SC) que, criado em 1957, por meio de decreto federal, está localizado na chamada "Maison de Joinville" ou "Palácio dos Príncipes", prédio tombado pelo IPHAN Instituto do Patrimônio Histórico e Artístico Nacional, desde 1939; apresenta em seu entorno, também, outros espaços museais. O casarão principal, construído aproximadamente em 1870, foi residência e sede da Colônia Dona Francisca, região anteriormente ocupada, desde 1851, por imigrantes e que daria origem ao município de Joinville, no estado de Santa Catarina (Museu Nacional, 2017).

A visita contou com monitoramento integral, iniciando pelo casarão principal e percorrendo todo o entorno da área. Os cursistas tiveram contato não somente com os cômodos que compõem o edifício principal, mas também com o mobiliário, vestimentas, fotografias, objetos de uso pessoal, vitrines de porcelanas e pratarias que foram utilizadas pelos moradores, representantes políticos do Império Brasileiro. Em seu entorno, destacam-se o "Auditório Dona Francisca" (local que servia de administração da então sede da Colônia Dona Francisca e onde foram recebidas as primeiras orientações da visita, conforme Fotografia 4), o "Galpão de Tecnologia Patrimonial" (máquinas e ferramentas de trabalho de imigrantes e luso-brasileiros), o "Galpão de Transportes" (meios de transporte utilizados desde a segunda metade do século XIX) e a "Casa Enxaimel" (construída basicamente pela técnica de madeiras encaixadas sem a utilização de pregos, representativa de uma moradia familiar de imigrantes desde meados do século XIX), conforme Fotografia 5, fruto de outro momento de registro coletivo com os cursistas. 
Fotografia 4 - Orientações de monitoria - Museu Nacional de Imigração e Colonização

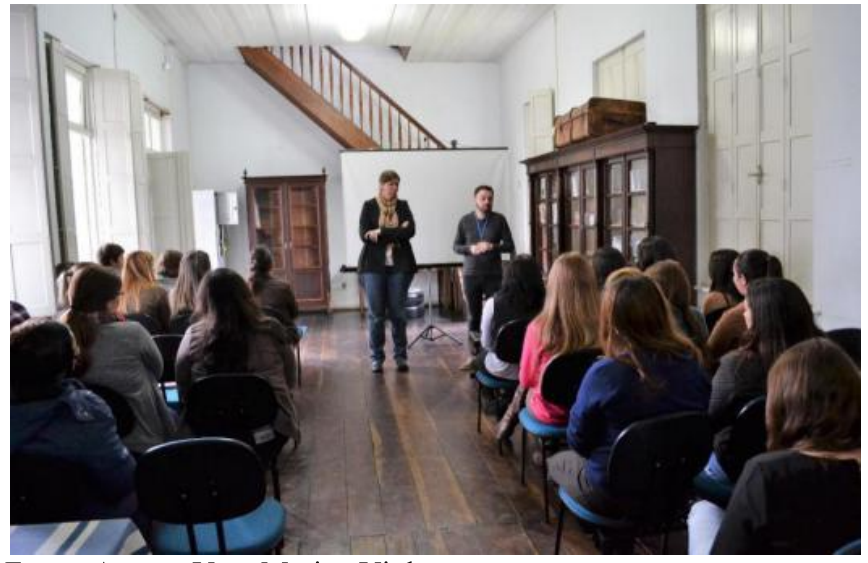

Fonte: Acervo Vera Marina Viglus

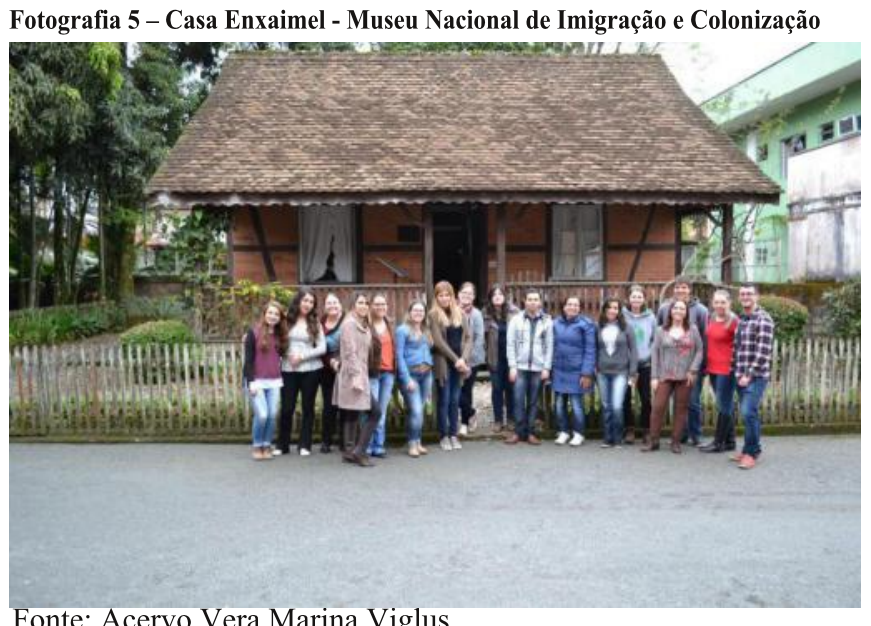

Fonte: Acervo Vera Marina Viglus

A partir do universo de elementos que sinalizam, de forma especial, para o cotidiano vivido, representado na Fotografia 6, bem como para questões de cunho político e econômico, foi possível dialogar sobre a amplitude do próprio conceito de educação, para além de fatores que remetam à escolarização, mas especialmente no âmbito familiar e social, tendo em conta vestígios de um tempo em que a educação escolar não se constituía como prioridade nas intenções do Estado no Brasil, seja no período imperial, seja no republicano.

Fotografia 6 - Vestígios do cotidiano de imigrantes - Museu Nacional de Imigração e Colonização

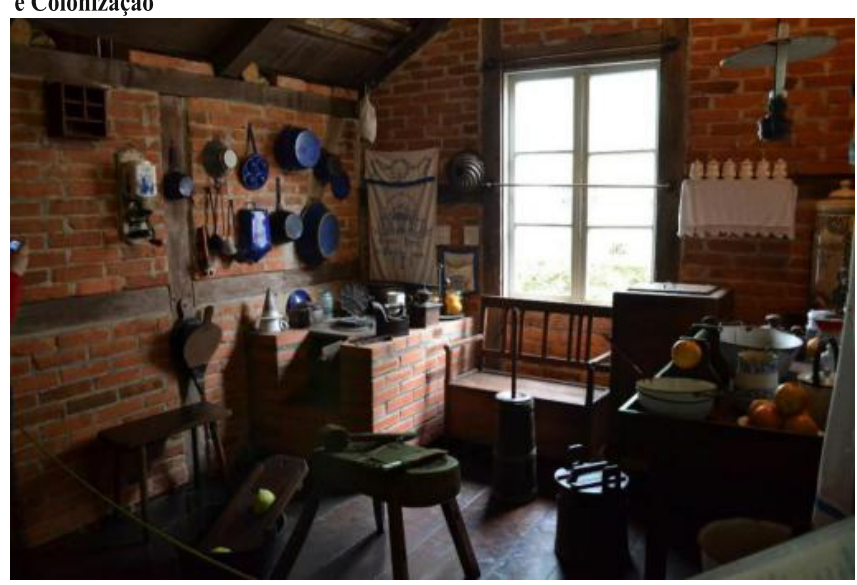

Fonte: Acervo Vera Marina Viglus

\section{Algumas considerações}

A partir da experiência vivenciada, possibilitouse pensar a articulação entre a atividade extensionista, o ensino e a pesquisa, já que a proposta em questão encontrou relevância acadêmica na formação de professores/as, bem como incentivo na formação de pesquisadores/as por meio de experiências educativas em espaços museais diversificados. Essas experiências foram sustentadas, especialmente, pela interação entre estudantes de graduação, pós-graduação e profisssionais responsáveis pelas visitações aos museus. Dessa forma, apontou-se para diferenciadas possibilidades de compreensão das diversas fontes possíveis para pesquisas correlacionadas à Memória, História e História da Educação, especialmente no âmbito do estudo do patrimônio cultural no Brasil.

Foi possível evidenciar, também, entre os integrantes, a necessidade de que se promovam ações que sirvam de incentivo às iniciativas de cunho cultural, já que foram bastante recorrentes, durante as visitas aos museus, questões que condizem ao cotidiano daqueles que se dedicam a esses espaços, seja pelo enfrentamento de questões diversas com vistas à uma estrutura física adequada ou pelas precárias condições de manutenção de acervos, por conta da falta ou dos poucos recursos destinados à área cultural no país, seja na promoção de ações que visem abrir, efetivamente, as portas ao público visitante, apontando tanto para silenciamentos e cristalizações como para diferenciadas formas e sentidos da memória.

Os instrumentos para a avaliação tiveram como critérios de pontuação a participação nas viagens de estudos e o relatório escrito entregue ao final das atividades propostas. Todavia, para além da avaliação proposta, a interação proporcionada foi bastante satisfatória, abrindo possibilidades para se pensar em novas propostas extensionistas, visando a problematização de questões de cunho acadêmico em correlação com ações culturais, que priorizem o viés da inserção social. Foi gratificante e significativo vivenciar a empolgação, o convívio e os momentos de aprendizado compartilhados entre os integrantes do curso de extensão, durante as visitações ao Museu Paranaense (Curitiba - PR) e ao Museu Nacional de Imigração e Colonização (Joinville - SC). 


\section{Referências}

BOURDIEU, Pierre. O amor pela arte: os museus de arte na Europa e seu público. São Paulo: USP; Porto Alegre: Zook, 2007.

HALBWACHS, Maurice. A memória coletiva. São Paulo: Vértice, 1990.

MUSEU Nacional de Imigração e Colonização. Disponível em $\quad<$ http://museudeimigracao.blogspot.com.br/p/blogpage_14.html $>$. Acesso em: 31 ago. 2017.

MUSEU PARANAENSE. Disponível em
$<$ http://www.museuparanaense.pr.gov.br/modules/conteudo/
conteudo.php?conteudo=48>. Acesso em: 31 ago. 2017 .

NORA, Pierre. Entre memória e história: a problemática dos lugares. Projeto História, São Paulo, n. 10, p. 7-39, 1993.
POLLAK, Michael. Memória, Esquecimento, Silêncio. Estudos Históricos. Vértice, Rio de Janeiro, v. 2, n.3, p. 3-15, 1989.

SANTOS, Myrian Sepúlveda dos. Museus brasileiros e política cultural. Revista Brasileira de Ciências Sociais, São Paulo, v. 19, n. 55, p. 53-72. Disponível em $<$ http://dx.doi.org/10.1590/S0102-69092004000200004>. Acesso em: 30 ago. 2017.

STEPHANOU, Maria. Problematizações em torno do tema memória e história da educação. História da Educação, Pelotas, v. 2, n. 4, p. 131-141. Disponível em $<\mathrm{http}: / /$ seer.ufrgs.br/asphe/article/view/30717>. Acesso em: 30 ago. 2017. 